\title{
Unanticipated critical findings on echocardiography in septic patients
}

\author{
Sarah J. Beesley ${ }^{1,2,6^{*}} \mathbb{D}$, Ezekiel Egan ${ }^{3}$, Michael J. Lanspa ${ }^{1,2,4}$, Emily L. Wilson ${ }^{1}$, Elliotte L. Hirshberg ${ }^{1,2,4,5}$, \\ Colin K. Grissom ${ }^{1,2,4}$, Rebecca Burk ${ }^{1,4}$ and Samuel M. Brown $n^{1,2,4}$
}

\begin{abstract}
Background: Echocardiography is increasingly performed among septic patients as a routine part of evaluation and management in the intensive care unit (ICU). The rate of unanticipated critical findings (e.g., severe left or right ventricular dysfunction or pericardial tamponade) on such echocardiograms is unknown. We evaluated a retrospective cohort of septic ICU patients in whom transthoracic echocardiography was performed as a routine part of sepsis management. In addition to identifying critical findings, we defined whether each critical finding was anticipated, and whether the clinical team responded to the critical finding. The primary outcome was rate of unanticipated critical findings, which we hypothesized would occur in fewer than $5 \%$ of patients. We also performed an exploratory analysis of the association between unanticipated critical finding and mortality, controlling for severity of illness.

Results: We studied 393 patients. Unanticipated critical findings were identified in 5\% (95\% Cl 3-7\%) of patients $(n=20)$. Among the 20 patients with unanticipated critical findings, a response to the unanticipated critical finding was identified in 12 (60\%) patients. An unanticipated critical finding was not significantly associated with 28-day mortality when controlling for admission APACHE II $(p=0.27)$.

Conclusions: Unanticipated critical findings on echocardiograms in septic ICU patients are uncommon. The potential therapeutic relevance of echocardiography to sepsis is more likely related to hemodynamic management than to traditional cardiac diagnoses. Research studies that employ blinded echocardiograms in septic patients may anticipate unblinding for critical findings approximately 1 in every 20 echocardiograms.
\end{abstract}

Keywords: Echocardiography, Intensive care, Sepsis, Septic shock

\section{Background}

Echocardiography is increasingly performed among patients with sepsis as a routine part of management [1-3]. Opinion and/or consensus statements in favor of broader application of focused critical care echocardiography and instructional guides [4-8] manifest increasing momentum in favor of the broad use of these focused echocardiograms. Critical care echocardiography now supports a board certification process [9-11].

\footnotetext{
*Correspondence: Sarah.beesley@imail.org

${ }^{6}$ Shock Trauma Intensive Care Unit, 5121 South Cottonwood Street,

Murray, UT 84107, USA

Full list of author information is available at the end of the article
}

Appropriateness criteria suggest that transthoracic echocardiogram (TTE) is appropriate in the case of shock or situations where TTE is likely to change management, and a variety of studies suggest that TTE identifies findings that change management [12-18]. Admittedly, these studies have either been in populations with high likelihood of relevant findings (e.g., perioperative management of cardiac surgery patients) or have been analyzed under the assumption that echocardiography should direct management and then reporting that echocardiography changes management [19]. Currently, the application of echocardiography in septic patients is often related to hemodynamic management, especially fluid administration [20-22]. 
However, for healthcare systems evaluating the implications of screening echocardiograms and for clinical researchers wondering how often a research echocardiogram may identify an unanticipated critical finding (such as severe left or right ventricular dysfunction or pericardial tamponade, which may necessitate new study procedures and/or unblinding), it is important to know how often an echocardiogram obtained for sepsis identifies an unexpected critical finding. In a prior study of an unselected ICU population $(N=467)$, a high proportion (36\%) of unanticipated cardiac abnormalities were identified on echocardiogram [23]. This study included many findings not normally considered critical and was not specific to sepsis patients.

We thus sought to clarify how often unanticipated critical findings are identified in the echocardiograms of septic patients admitted to the ICU. We performed an analysis of patients in our registry of septic patients in whom TTE had been performed as a routine part of the management of sepsis. We hypothesized that unanticipated critical findings on echocardiogram would be present in less than $5 \%$ of echocardiograms.

\section{Methods}

\section{Patients}

Participants included patients (age at least 18 years) with severe sepsis or septic shock (Sepsis-2 definition [24], which applied at the time of cohort assembly) admitted to study ICUs between October 2012 and November 2015. Patients had clinically suspected infection defined by study coordinator chart review, two or more systemic inflammatory response syndrome criteria and had either shock (systolic blood pressure (SBP) $<90 \mathrm{mmHg}$ despite IVF challenge of $\geq 20 \mathrm{~mL} / \mathrm{kg}$ or infusion of vasopressors) or severe sepsis (lactate $>4 \mathrm{mmol} / \mathrm{L}$ ) $[24,25]$. We included only patients who had an echocardiogram obtained within $24 \mathrm{~h}$ of admission; in the study ICU, this is approximately $50 \%$ of patients with sepsis and $75 \%$ of patients with septic shock (unpublished data). Exclusion criteria included known pregnancy, primary diagnosis of acute coronary syndrome or major cardiac dysrhythmia, or known alternative diagnosis for shock (trauma, anaphylaxis, hemorrhage) on coordinator review, confirmed by an investigator.

\section{Critical findings on echocardiogram}

We reviewed all echocardiogram reports to identify critical findings. Echocardiograms were performed by trained, credentialed sonographers and over-read by either board-certified cardiologists or Level II critical care echocardiographers who were testamurs of the National Board of Echocardiography ASCeXAM. We employed the American Society of Echocardiography definitions of critical findings: (1) cardiac tamponade or new large pericardial effusion, (2) new left ventricular ejection fraction $(\mathrm{LVEF})<30 \%$, (3) new severe right ventricular systolic dysfunction [26], (4) evidence of aortic dissection, (5) new cardiac masses or thrombi, or (6) new, severe valvular dysfunction [27]. We also included (7) left ventricular outflow obstruction or hypertrophic cardiomyopathy with velocities $>4 \mathrm{~m} / \mathrm{s}$, or (8) moderate or greater right to left shunt [28], as those may be immediately relevant in a critical care environment.

We defined whether the critical finding was anticipated or not based on the following algorithm: (1) was the finding present on a prior echocardiogram? (if so $\longrightarrow$ anticipated); or (2) was the finding referenced in clinical documentation as being of diagnostic concern before the echocardiogram had been performed (if so $\longrightarrow$ anticipated). See process outline in Fig. 1. Of note, when a vegetation was identified on TTE, this was not considered an unanticipated critical finding if endocarditis was considered prior to obtaining the TTE; we considered positive blood cultures with a typical organism before the echocardiogram was ordered as suggesting that endocarditis was under diagnostic consideration.

We also evaluated the response to the identification of an unanticipated critical finding. If the finding was unanticipated, the clinical response was noted in the following categories: no response, monitoring response, or intervention. No response means that we could find no evidence in the electronic medical record (EMR) that the treating team incorporated the critical finding into their monitoring or management. Monitoring response means that the EMR indicated either increased or additional monitoring explicitly tied to the critical finding. This included both non-invasive monitoring (e.g., repeat echocardiogram or other imaging), and invasive monitoring (e.g., left or right heart catheterization). Intervention was considered present if there was a change in treatment associated with the critical finding and included both non-invasive intervention (e.g., antibiotics, afterload reduction, diuresis) and invasive intervention (e.g., percutaneous coronary intervention, transcatheter aortic valve replacement, surgery).

A critical finding was designated as a false-positive finding if subsequent testing refuted the apparent findings from the initial echocardiogram report.

\section{Analysis plan}

We estimated a priori that the proportion of unanticipated critical findings would be $<5 \%$. We estimated the precision of our estimate to be within $2.3 \%$ for a proportion of $5 \%$ with a sample size of 390 and a $95 \%$ confidence level. This was calculated using PASS 12.0.3 [29]. 


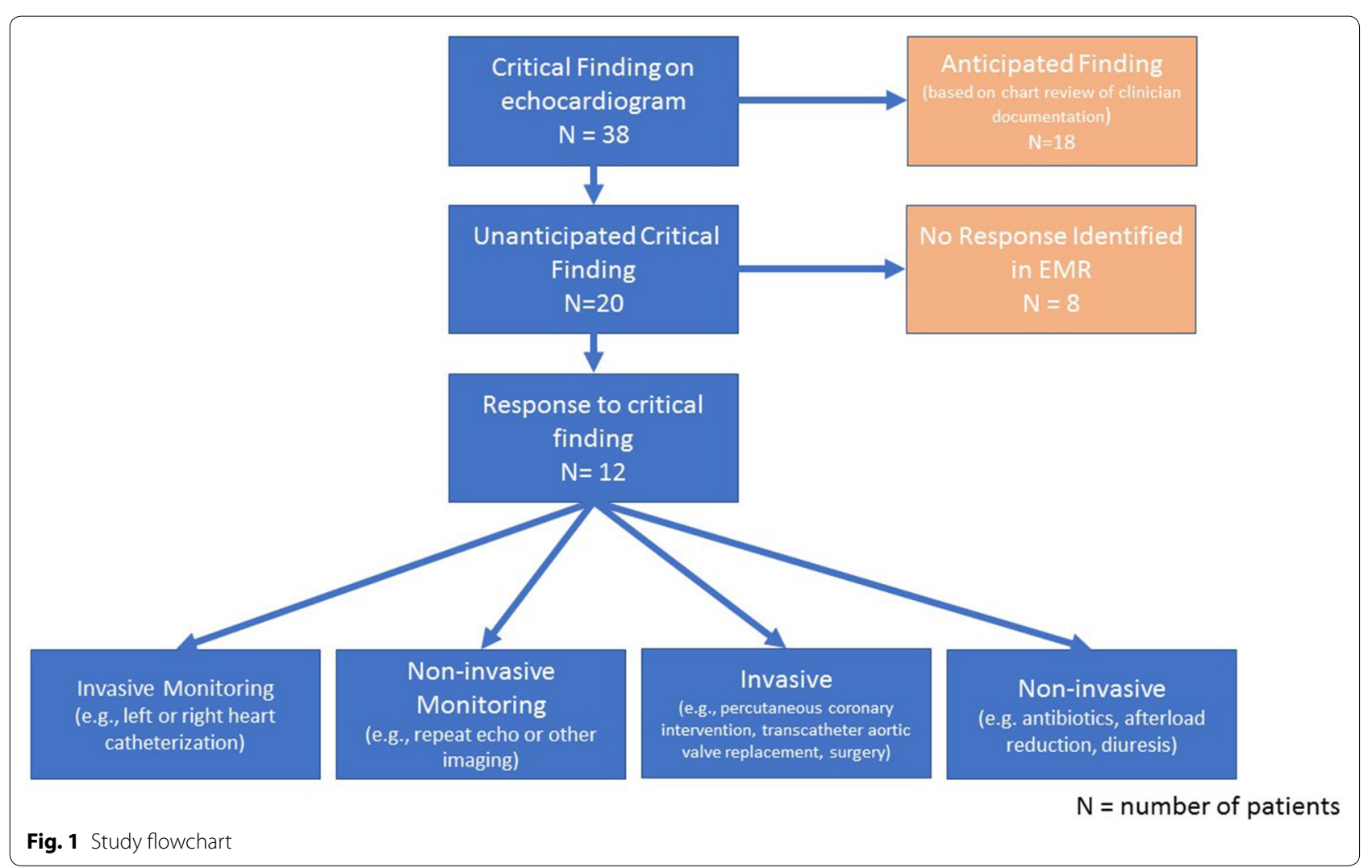

The prespecified primary analysis was to estimate the proportion of unanticipated critical findings identified on TTE. As a secondary exploratory analysis, we evaluated the association between critical findings and 28-day mortality, adjusted for severity of illness, using multivariate logistic regression. All analyses were conducted using the R Statistical Package, version 3.5.1 [30].

The study was approved with waiver of informed consent by the Intermountain Institutional Review Board (Intermountain IRB \#1009957).

\section{Results}

This cohort of septic patients included 393 patients. There were 222 (56\%) patients in shock (systolic blood pressure $<90 \mathrm{mmHg}$ ) at the time of the echocardiogram; 151 of these were on vasopressors. Mean APACHE II score for the cohort was $26(\mathrm{SD}=10)$. Overall 28-day mortality was $24 \%(n=93)$.

Unanticipated critical findings were identified in $5 \%$ (95\% CI $3-7 \%)$ of patients $(n=20)$. In total, 40 critical findings were identified on TTE in 38 (10\%) patients (two patients had two critical findings). Of these 40 findings, 21 (53\%) were unanticipated (see Table 1). Twelve of the 19 anticipated critical findings had been identified on prior echo, and the remaining 7 anticipated critical findings were previously suspected by the treating team based on EMR documentation.

Out of the 20 patients with unanticipated critical findings, a response to the unanticipated critical finding was identified in $12(60 \%)$ patients. The response was noninvasive monitoring in 11 patients (primarily repeat echocardiograms) and non-invasive intervention in 6 patients (primarily blood pressure or fluid management). Some patients had multiple responses to the unanticipated critical findings, i.e., both a change in monitoring and a non-invasive intervention. No patients with unanticipated critical findings underwent either invasive monitoring or invasive interventions for that finding. Four unanticipated critical findings (one aortic dissection and three intracardiac masses) were found to be falsepositives on repeat imaging with either $\mathrm{CT}$ angiogram or echocardiogram. In the 8 patients whose critical finding elicited no response, $50 \%$ died within $48 \mathrm{~h}$ of ICU admission; among the 12 patients whose critical findings elicited a response, $1(8 \%)$ died within $48 \mathrm{~h}$ of ICU admission.

An unanticipated critical finding was not significantly associated with 28-day mortality when adjusted for admission APACHE II $(p=0.27)$. A critical finding (whether anticipated or unanticipated) on echocardiogram was also not significantly associated with 28-day 
Table 1 Critical findings

\begin{tabular}{lcc}
\hline Type of critical finding & Critical finding $(\boldsymbol{N = 4 0 )}$ & $\begin{array}{l}\text { Unanticipated } \\
\text { critical finding } \\
(\boldsymbol{N}=\mathbf{2 1})\end{array}$ \\
\hline Tamponade & & $0(0 \%)$ \\
New depressed LV EF $<30 \%$ & $0(0 \%)$ & $7(33 \%)$ \\
New severe right ventricular systolic dysfunction & $9(22 \%)$ & $2(9 \%)$ \\
Aortic dissection & $5(12 \%)$ & $1(5 \%)$ \\
Cardiac mass, thrombus or vegetation & $1(2 \%)$ & $7(33 \%)$ \\
LVOT obstruction or HCM, $>4$ m/s & $13(32 \%)$ & $2(9 \%)$ \\
Right to left shunt, moderate or severe & $3(7 \%)$ & $1(5 \%)$ \\
Severe valvular dysfunction & $1(2 \%)$ & $1(5 \%)$
\end{tabular}

Data presented as $N$ (\%); $N$ represents number of critical findings (there are two patients with two critical findings)

LVEF left ventricular ejection fraction, LVOT left ventricular outflow track, HCM hypertrophic cardiomyopathy

mortality when adjusted for admission APACHE II score $(p=0.85)$.

\section{Discussion}

As echocardiograms are frequently performed both clinically and within research protocols, we sought to identify how often the results of an echocardiogram performed among septic ICU patients were unexpected and critical. In our large single-center cohort that makes extensive use of echocardiography in the early management of septic patients, unanticipated critical findings were identified in $5 \%$ of septic patients. This confirmed our prespecified hypothesis before this study that approximately 1 in 20 echocardiograms in septic patients identified an unanticipated critical finding. Mortality in this study is comparable to other studies on similar populations [31,32].

Our findings provide useful estimates for researchers performing blinded echocardiograms in septic patients of the probability that unblinding may be required. Our findings also suggest to clinicians how often unexpected results may be anticipated on echocardiograms performed as part of the management of sepsis. We also believe that our findings suggest that the key target for building evidence for efficacy of critical care echocardiography in septic patients will emphasize hemodynamic guidance, which is likely to be much more important than unanticipated diagnoses.

Our findings contribute to preexisting literature on critical care echocardiography. In a study of pediatric ICU patients, echocardiography introduced a new diagnosis unrelated to the echo indication in 13\%; an echo ordered as stat was more likely to change management and diagnosis than a routinely ordered echo [33]. In another study of critically ill patients, TTE changed diagnosis in $19 \%$ of cases and management in $34 \%$ of cases with "adequate clinical data". TTE changed diagnosis in
$56 \%$ of cases and management in $58 \%$ of cases with "inadequate clinical data" [34]. For comparison, patients presenting to ED with chest pain and shortness of breath, TTE changed diagnosis in $25 \%$ of cases and management in $37 \%$ of cases. It also increased the diagnosing physician's confidence in diagnosis and management [35]. For comparison, rates of unanticipated findings in outpatients undergoing echocardiography for dyspnea or chest pain were found to be $22 \%$ in one study of 368 outpatient TTEs [36]. These comparable studies reflect a variety of settings and methods, but with the similar conclusion that, occasionally, unanticipated findings that change management may be identified by echocardiogram.

Our study findings may not be fully generalizable because they represent patients treated at one academic referral center and was performed on a retrospective cohort. Many emergency room physicians at this center have an interest in point of care ultrasound and patients are also often frequently ultrasounded at the bedside while in the emergency room. This could have potentially led to an underestimation of unanticipated critical findings compared to other sites if findings were identified prior to ICU transfer and documented in the medical chart. We also note the contextuality of our findings: the rate of unanticipated findings on echo may correlate with the breadth of clinicians' differential diagnoses. At this academic referral center, ICU patients are generally cared for by a team of clinicians prior to ICU transfer, as well as an ICU resident, fellow and attending once in the ICU; having several different clinicians involved in creating and documenting a differential diagnosis may make this less of an issue, although we did not formally address this question. In addition, while a TTE is generally obtained in septic patients admitted to the study ICU, if sicker patients at higher risk of an unanticipated critical 
finding preferentially underwent echocardiography, our estimate of the prevalence of such findings may be inaccurately high. We did not perform a bubble study on all patients, so the rate of right to left shunt in this population might have been underestimated. We acknowledge that our study is not adequately powered to determine whether unanticipated critical findings-or responses to them-are associated with mortality; much larger cohorts would be required for such an analysis.

\section{Conclusion}

Unanticipated critical findings on routine echocardiograms in septic ICU patients are uncommon. The potential relevance of echocardiography to sepsis management is more likely related to hemodynamic management than to traditional cardiologic diagnoses. Secondarily, research studies that employ blinded echocardiograms in septic patients may anticipate unblinding of approximately 1 in every 20 echocardiograms based on the unanticipated critical findings.

\begin{abstract}
Abbreviations
APACHE: Acute Physiology and Chronic Health Evaluation; CT: Computed tomography; Cl: Confidence interval; EMR: Electronic medical record; IRB: Institutional Review Board; ICU: Intensive care unit; IVF: Intravenous fluid; LVEF: Left ventricular ejection fraction; SD: Standard deviation; SBP: Systolic blood pressure; TTE: Transthoracic echocardiogram.
\end{abstract}

\section{Acknowledgements}

Not applicable.

\section{Authors' contributions}

SJB, EE, SMB, EH, ML, and CG designed the study. EE, SJB, ML, and SMB analyzed and interpreted the data. SJB, ML, and SMB drafted the report, and all other authors revised it. All authors read and approved the final manuscript.

\section{Funding}

None.

\section{Availability of data and materials}

The datasets generated and/or analyzed during the current study are not publicly available due to lack of consent from participants regarding data sharing.

\section{Ethics approval and consent to participate}

The Intermountain Institutional Review Board approved this study with waiver of informed consent.

\section{Consent for publication}

Not applicable.

\section{Competing interests}

The authors declare that they have no competing interests.

\footnotetext{
Author details

1 Pulmonary Division, Intermountain Medical Center, Salt Lake City, UT, USA. 2 Pulmonary Division, University of Utah School of Medicine, Salt Lake City, UT, USA. ${ }^{3}$ University of Utah School of Medicine, Salt Lake City, UT, USA. ${ }^{4}$ Critical Care Echocardiography Service, Intermountain Medical Center, Salt Lake City, UT, USA. ${ }^{5}$ Department of Pediatrics, University of Utah School of Medicine, Salt Lake City, UT, USA. ${ }^{6}$ Shock Trauma Intensive Care Unit, 5121 South Cottonwood Street, Murray, UT 84107, USA.
}

Received: 15 October 2019 Accepted: 13 February 2020

Published online: 02 April 2020

\section{References}

1. Griffee MJ, Merkel MJ, Wei KS (2010) The role of echocardiography in hemodynamic assessment of septic shock. Crit Care Clin 26(2):365-382. https://doi.org/10.1016/j.ccc.2010.01.001 (Table of contents)

2. McLean AS (2016) Echocardiography in shock management. Crit Care 20:275. https://doi.org/10.1186/s13054-016-1401-7

3. Schmidt GA (2009) ICU ultrasound. The coming boom. Chest 135(6):1407-1408. https://doi.org/10.1378/chest.09-0502

4. Beaulieu Y (2007) Bedside echocardiography in the assessment of the critically ill. Crit Care Med 35(5 Suppl):S235-S249

5. Beaulieu Y, Marik PE (2005) Bedside ultrasonography in the ICU: part 2. Chest 128(3):1766-1781. https://doi.org/10.1378/chest.128.3.1766

6. Beaulieu Y, Marik PE (2005) Bedside ultrasonography in the ICU: part 1. Chest 128(2):881-895

7. Donovan KD, Colreavy F (1999) Echocardiography in intensive care: the basics. Part I. Crit Care Resusc 1(3):291-295

8. Donovan KD, Colreavy F (1999) Echocardiography in intensive care: the basics. Part II. Crit Care Resusc 1(3):296-310

9. Mayo PH, Beaulieu Y, Doelken P, Feller-Kopman D, Harrod C, Kaplan A, Oropello J, Vieillard-Baron A, Axler O, Lichtenstein D, Maury E, Slama M, Vignon P (2009) American College of Chest Physicians/La Societe de Reanimation de Langue Francaise statement on competence in critical care ultrasonography. Chest 135(4):1050-1060. https://doi.org/10.1378/ chest.08-2305

10. Skaarup SH, Laursen CB, Bjerrum AS, Hilberg O (2017) Objective and structured assessment of lung ultrasound competence. A multispecialty Delphi consensus and construct validity study. Ann Am Thorac Soc 14(4):555-560. https://doi.org/10.1513/annalsats.201611-894oc

11. Vieillard-Baron A, Mayo PH, Vignon P, Cholley BP, Slama M, Pinsky M, McLean A, Choi G, Beaulieu Y, Arntfield R, Koenig S (2014) International consensus statement on training standards for advanced critical care echocardiography. Intensive Care Med 40(5):654-666. https://doi. org/10.1007/s00134-014-3228-5

12. Chenzbraun A, Pinto FJ, Schnittger I (1994) Transesophageal echocardiography in the intensive care unit: impact on diagnosis and decisionmaking. Clin Cardiol 17(8):438-444

13. Colreavy FB, Donovan K, Lee KY, Weekes J (2002) Transesophageal echocardiography in critically ill patients. Crit Care Med 30(5):989-996

14. Heidenreich PA, Stainback RF, Redberg RF, Schiller NB, Cohen NH, Foster E (1995) Transesophageal echocardiography predicts mortality in critically ill patients with unexplained hypotension. J Am Coll Cardiol 26(1):152-158

15. Benjamin E, Griffin K, Leibowitz AB, Manasia A, Oropello JM, Geffroy V, DelGiudice R, Hufanda J, Rosen S, Goldman M (1998) Goal-directed transesophageal echocardiography performed by intensivists to assess left ventricular function: comparison with pulmonary artery catheterization. J Cardiothorac Vasc Anesth 12(1):10-15

16. Bruch C, Comber M, Schmermund A, Eggebrecht H, Bartel T, Erbel R (2003) Diagnostic usefulness and impact on management of transesophageal echocardiography in surgical intensive care units. Am J Cardiol 91(4):510-513

17. Vignon P, Mentec H, Terre S, Gastinne H, Gueret P, Lemaire F (1994) Diagnostic accuracy and therapeutic impact of transthoracic and transesophageal echocardiography in mechanically ventilated patients in the ICU. Chest 106(6):1829-1834

18. American College of Cardiology Foundation Appropriate Use Criteria Task F, American Society of E, American Heart A, American Society of Nuclear C, Heart Failure Society of A, Heart Rhythm S, Society for Cardiovascular A, Interventions, Society of Critical Care M, Society of Cardiovascular Computed T, Society for Cardiovascular Magnetic R, American College of Chest P, Douglas PS, Garcia MJ, Haines DE, Lai WW, Manning WJ, Patel AR, Picard MH, Polk DM, Ragosta M, Parker Ward R, Weiner RB (2011) ACCF/ ASE/AHA/ASNC/HFSA/HRS/SCAI/SCCM/SCCT/SCMR 2011 appropriate use criteria for echocardiography. A report of the American College of Cardiology Foundation Appropriate Use Criteria Task Force, American 
Society of Echocardiography, American Heart Association, American Society of Nuclear Cardiology, Heart Failure Society of America, Heart Rhythm Society, Society for Cardiovascular Angiography and Interventions, Society of Critical Care Medicine, Society of Cardiovascular Computed Tomography, Society for Cardiovascular Magnetic Resonance American College of Chest Physicians. J Am Soc Echocardiogr 24(3):229-267. https ://doi.org/10.1016/j.echo.2010.12.008

19. Manasia AR, Nagaraj HM, Kodali RB, Croft LB, Oropello JM, Kohli-Seth R, Leibowitz AB, DelGiudice R, Hufanda JF, Benjamin E, Goldman ME (2005) Feasibility and potential clinical utility of goal-directed transthoracic echocardiography performed by noncardiologist intensivists using a small hand-carried device (SonoHeart) in critically ill patients. J Cardiothorac Vasc Anesth 19(2):155-159

20. Beigel R, Cercek B, Arsanjani R, Siegel RJ (2014) Echocardiography in the use of noninvasive hemodynamic monitoring. J Crit Care 29(1):184. e181-184.e188. https://doi.org/10.1016/j.jcrc.2013.09.003

21. Price S, Nicol E, Gibson DG, Evans TW (2006) Echocardiography in the critically ill: current and potential roles. Intensive Care Med 32(1):48-59. https://doi.org/10.1007/s00134-005-2834-7

22. Boyd JH, Sirounis D, Maizel J, Slama M (2016) Echocardiography as a guide for fluid management. Crit Care 20(1):274. https://doi.org/10.1186/ s13054-016-1407-1

23. Bossone E, DiGiovine B, Watts S, Marcovitz PA, Carey L, Watts C, Armstrong WF (2002) Range and prevalence of cardiac abnormalities in patients hospitalized in a medical ICU. Chest 122(4):1370-1376

24. Levy MM, Fink MP, Marshall JC, Abraham E, Angus D, Cook D, Cohen J, Opal SM, Vincent JL, Ramsay G (2003) 2001 SCCM/ESICM/ACCP/ATS/SIS international sepsis definitions conference. Crit Care Med 31(4):12501256. https://doi.org/10.1097/01.CCM.0000050454.01978.3B

25. Singer M, Deutschman CS, Seymour CW, Shankar-Hari M, Annane D, Bauer M, Bellomo R, Bernard GR, Chiche JD, Coopersmith CM, Hotchkiss RS, Levy MM, Marshall JC, Martin GS, Opal SM, Rubenfeld GD, van der Poll T, Vincent JL, Angus DC (2016) The third international consensus definitions for sepsis and septic shock (Sepsis-3). JAMA 315(8):801-810. https:// doi.org/10.1001/jama.2016.0287

26. McConnell MV, Solomon SD, Rayan ME, Come PC, Goldhaber SZ, Lee RT (1996) Regional right ventricular dysfunction detected by echocardiography in acute pulmonary embolism. Am J Cardiol 78(4):469-473

27. Picard MH, Adams D, Bierig SM, Dent JM, Douglas PS, Gillam LD, Keller AM, Malenka DJ, Masoudi FA, McCulloch M, Pellikka PA, Peters PJ, Stainback RF, Strachan GM, Zoghbi WA (2011) American Society of Echocardiography recommendations for quality echocardiography laboratory operations. J Am Soc Echocardiogr 24(1):1-10. https://doi.org/10.1016/j. echo.2010.11.006

28. Chauvet JL, El-Dash S, Delastre O, Bouffandeau B, Jusserand D, Michot JB, Bauer F, Maizel J, Slama M (2015) Early dynamic left intraventricular obstruction is associated with hypovolemia and high mortality in septic shock patients. Crit Care. https://doi.org/10.1186/s13054-015-0980-z

29. Hintze J (2013) PASS 12. NCSS, LLC, Kaysville

30. R Development Core Team (2014) R: A language and environment for statistical computing. R Foundation for Statistical Computing, Vienna, Austria

31. Capuzzo M, Volta C, Tassinati T, Moreno R, Valentin A, Guidet B, lapichino G, Martin C, Perneger T, Combescure C, Poncet A, Rhodes A, Working Group on Health Economics of the European Society of Intensive Care M (2014) Hospital mortality of adults admitted to Intensive Care Units in hospitals with and without Intermediate Care Units: a multicentre European cohort study. Crit Care 18(5):551. https://doi.org/10.1186/s1305 4-014-0551-8

32. Liu V, Escobar GJ, Greene JD, Soule J, Whippy A, Angus DC, Iwashyna TJ (2014) Hospital deaths in patients with sepsis from 2 independent cohorts. JAMA 312(1):90-92. https://doi.org/10.1001/jama.2014.5804

33. Kutty S, Attebery JE, Yeager EM, Natarajan S, Li L, Peng Q, Truemper E, Hammel JM, Danford DA (2014) Transthoracic echocardiography in pediatric intensive care: impact on medical and surgical management. Pediatr Crit Care Med 15(4):329-335. https://doi.org/10.1097/PCC.0000000000 000099

34. Stanko LK, Jacobsohn E, Tam JW, De Wet CJ, Avidan M (2005) Transthoracic echocardiography: impact on diagnosis and management in tertiary care intensive care units. Anaesth Intensive Care 33(4):492-496. https://doi.org/10.1177/0310057×0503300411

35. Levitt MA, Jan BA (2002) The effect of real time 2-D-echocardiography on medical decision-making in the emergency department. J Emerg Med 22(3):229-233

36. Kirkpatrick JN, Ky B, Rahmouni HW, Chirinos JA, Farmer SA, Fields AV, Ogbara J, Eberman KM, Ferrari VA, Silvestry FE, Keane MG, Opotowsky AR, Sutton MS, Wiegers SE (2009) Application of appropriateness criteria in outpatient transthoracic echocardiography. J Am Soc Echocardiogr 22(1):53-59. https://doi.org/10.1016/j.echo.2008.10.020

\section{Publisher's Note}

Springer Nature remains neutral with regard to jurisdictional claims in published maps and institutional affiliations.

\section{Submit your manuscript to a SpringerOpen ${ }^{\circ}$ journal and benefit from:}

- Convenient online submission

- Rigorous peer review

- Open access: articles freely available online

- High visibility within the field

- Retaining the copyright to your article

Submit your next manuscript at $\boldsymbol{\nabla}$ springeropen.com 